Revista de
Economild
Contemporâned

\title{
A QUESTÃO DA DESIGUALDADE MULTIDIMENSIONAL: DISCUTINDO A CONSTRUÇÃO DE UM INDICADOR
}

\author{
Henrique Rogê Batista ${ }^{a}$ \\ Maria de Lourdes Rollemberg Mollo ${ }^{b}$

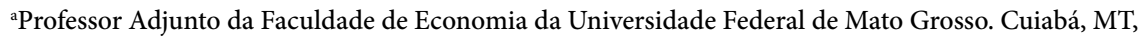 \\ Brasil. ORCID: https://orcid.org/0000-0002-0049-1589. \\ 'Professora Titular da Faculdade de Economia da Universidade de Brasília. Brasília, DF, Brasil. \\ Pesquisadora do CNPq. ORCID: https://orcid.org/0000-0002-4303-6914. \\ Recebido em 04 janeiro 2018 \\ Aceito em 11 março 2020
}

RESUMO: A abordagem multidimensional da desigualdade parte da concepção de que a renda não é o único determinante do padrão de vida dos indivíduos. Este artigo visa discutir a posição relativamente marginal do debate sobre a desigualdade na economia e destacar as formas agregada e desagregada de construir um índice de desigualdade multidimensional. Por meio da literatura sobre $\mathrm{o}$ assunto, $\mathrm{o}$ artigo analisa as controvérsias econômicas sobre a desigualdade, de forma a justificar a escolha das variáveis, dimensões ou atributos a serem incluídos no indicador a ser construído com o objetivo de informar adequadamente as políticas públicas que buscam a redução do problema.

PALAVRAS-CHAVE: desigualdade; desigualdade multidimensional; índices de desigualdade.

CLASSIFICAÇÃO JEL: D3; D6; I3. 


\title{
MULTIDIMENSIONAL INEQUALITY: DISCUSSING THE DEVELOPMENT OF AN INDEX
}

\begin{abstract}
The multidimensional approach of inequality presumes that income is not the only determinant of the life's standard of individuals. This article discusses the relatively marginal position of inequality in economics and highlights the aggregate and disaggregate ways of building a multidimensional index of inequality. Based on the literature on the subject, it analyzes the economic controversies about inequality to justify the choice of variables, dimensions, and attributes to be included in the index of multidimensional index, as the goal is to inform better the political policies aimed to reduce it.
\end{abstract}

KEYWORDS: inequality; multidimensional inequality; inequality index. 


\section{INTRODUÇÃO}

Estudos sobre a desigualdade justificam-se pela relevância do tema na atualidade, tanto internacionalmente quanto no contexto socioeconômico brasileiro. Diante das limitações dos vários métodos de construção de índices de desigualdade, torna-se importante avançar na elaboração de alternativas que permitam análises mais profundas e conceitualmente mais abrangentes do problema, como é o caso, com a construção de um índice de desigualdade multidimensional.

Essa demanda se apresenta num contexto em que a abordagem unidimensional monopoliza os debates sobre pobreza e desigualdade no Brasil e, do ponto de vista da renda, em que a desigualdade decresceu nos últimos anos, ao contrário da tendência concentradora observada desde a ditadura militar (CAMPELLO et al., 2018; NERI, 2011).

De acordo com as estatísticas disponíveis desde 1960, o ritmo da redução da desigualdade de renda documentada depois de 2001 é inédito, destacando-se a mitigação da pobreza (NERI, 2011). As causas por trás dessa queda recente são múltiplas e não é objetivo deste trabalho apurá-las, todavia, cabe citar sua dinâmica, que conforme Dedecca (2015) se discerne três momentos: i) 1999-2003: sustentação do rendimento dos estratos inferiores da renda quando se reduziu o rendimento nos estratos médios e alto; ii) 2004-2008: elevação da renda para todos os estratos, sendo que para os estratos inferiores, a elevação foi mais rápida e; iii) desde 2009: reiteração das características do período anterior, embora num contexto de instabilidade de crescimento da economia brasileira. ${ }^{1}$

Mesmo diante dessa redução da pobreza e da desigualdade de renda, na comparação internacional, a parcela da população com privação da renda ainda é elevada no país, que mantém, para essa dimensão, altos patamares de desigualdade (FERREIRA, 2017). Cabe ressaltar, neste contexto, que os estudos sobre desigualdade de renda avançaram consideravelmente no Brasil, o que permitiu um retrato mais fidedigno da distribuição de renda do país. Esses avanços concentram-se em vários aspectos que demandariam um trabalho específico para abordá-los. Vale, entretanto, destacar três deles:

1 Complementando a análise, pode-se observar o acréscimo dos gastos do governo no Brasil entre 2003 e 2009, em particular os gastos sociais. Apesar de haver um debate na literatura sobre os gargalos da oferta desses serviços públicos, eles foram relevantes para explicar a redução da desigualdade. Isso se dá num contexto em que a experiência recente tem mostrado que a redistribuição via gastos é mais eficaz e se observa menos resistência quanto à sua implementação (SILVEIRA et al., 2013). Em particular, os gastos públicos sociais que têm um caráter mais progressivo respondem por uma redução importante da desigualdade (SILVEIRA, 2012). Em Trovão (2015), outras variáveis explicativas e recortes temporais para explicar a redução da desigualdade de renda são apresentados. Embora não constitua o objetivo deste artigo discutir a redução da desigualdade de renda, citamos ainda Dedecca (2015) e Silveira (2012) como referências importantes. 
i) as contribuições de Medeiros (2005) e Medeiros, Souza e Castro (2015) abordando o estrato superior da renda; ii) Campello et al. (2018), que analisa também um extremo da privação, dessa vez considerando os mais pobres iii) os efeitos distributivos da incorporação monetária do acesso aos serviços de educação e saúde públicos, de Silveira (2012 e 2008).

Evidencia-se que a insuficiência da renda, tomando o indivíduo como unidade de observação, está acompanhada da privação em outras dimensões da vida: educação, saneamento básico, seguridade social e participação política, por exemplo (BATISTA, 2018; STIGLITZ, 2014). Ou seja, uma parcela considerável da população brasileira ainda é desprovida de direitos básicos, e tomar uma cesta de bens e serviços para caracterizar a distribuição e a privação faz-se necessário (BATISTA, 2018; CAMPELLO et al., 2018; LUGO, 2005).

A desigualdade deve ser interpretada como um elemento que é consequência e causa de vulnerabilidade social. Reconhecer a existência da desigualdade é admitir a existência de uma massa da população vivendo em situação de vulnerabilidade em várias esferas da vida (STIGLITZ, 2014). Assim, este estudo deve ser visto do ponto de vista moral, econômico e em termos de participação política, que condicionam o desenvolvimento humano dada a pluralidade de espaços e indivíduos (SEN, 1973; STIGLITZ, 2014). ${ }^{2}$

A análise da desigualdade multidimensional deve-se a essa percepção da insuficiência de uma variável, geralmente a renda ou o consumo, para determinar sozinha a satisfação ou a realização do indivíduo, ou unidade de observação, quanto à sua qualidade de vida. A esse respeito, o debate acadêmico tem convergido para o reconhecimento da necessidade de uma gama de variáveis para qualificar o padrão de vida das pessoas.

Tendo isso em vista, o objetivo deste artigo é discutir a construção de um índice de desigualdade multidimensional, nas versões atributo por atributo e agregada. Para tanto, é necessário, em primeiro lugar, justificar a importância e a escolha do tema desigualdade. Em segundo lugar, é preciso discutir o porquê de analisá-la em seu caráter multidimensional, de forma a elucidar algumas preocupações e cuidados de ordem teórica, que orientem a escolha dos atributos a serem utilizados. Em terceiro lugar, é preciso descrever as

2 Depois da Segunda Guerra Mundial, assistiu-se nos países desenvolvidos a uma mudança de paradigma da tributação com relação à distribuição. Isso se deu no contexto do acréscimo da oferta pública e da construção do Estado de Bem-Estar (SILVEIRA; PASSOS; GUEDES, 2018). A posição do Brasil, nesse contexto, apesar de alinhada à eficiência, competitividade e equidade horizontal, por questões estruturais, foi menos progressista na estruturação tributária, o que mostra o potencial de melhoria da política fiscal, em particular quanto aos gastos sociais, sobre os números da pobreza e desigualdade (SILVEIRA; PASSOS; GUEDES, 2018; SILVEIRA et al., 2013). 
especificidades de cada abordagem, agregada e desagregada, no sentido das informações geradas por cada uma delas enquanto guias para políticas públicas.

A segunda seção deste artigo discute a questão da desigualdade do ponto de vista econômico. Nela, apresentamos divergências teóricas que fazem com que, por um lado, a desigualdade seja um tema pouco importante para a ortodoxia econômica. Por outro lado, trata-se de, adicionando uma concepção econômica heterodoxa, apreender a desigualdade como importante problema a exigir políticas públicas voltadas para sua redução, o que requer um índice multidimensional para orientá-las. Essa compreensão é também fundamental para melhor definir as variáveis e dimensões ou atributos a serem contemplados na construção do índice de desigualdade multidimensional.

$\mathrm{Na}$ terceira seção, resenharemos algumas contribuições para o avanço do debate sobre o caráter multidimensional da desigualdade, tendo em vista que se trata de uma literatura ainda incipiente. A partir dessa revisão de literatura e dos requisitos que ela propõe para a escolha das dimensões ou atributos a serem usados na construção do índice, elencaremos alguns que nos parecem importantes, justificando-os.

$\mathrm{Na}$ quarta seção, é apresentada uma análise metodológica dos principais trabalhos empíricos sobre o tema, a fim de deixar clara a complementariedade entre as abordagens desagregada e agregada de construção do índice, justificando cada uma delas e sua análise conjunta. Ao final, algumas considerações serão apresentadas a título de conclusão.

\section{O TRATAMENTO DA DESIGUALDADE NAS TEORIAS ECONÔMICAS}

Muito tem sido escrito sobre a questão da desigualdade econômica nos dias atuais. Isso se deve, particularmente, ao seu crescimento de forma ampla nos anos mais recentes, uma vez que, salvo pequenas exceções, ela cresce no mundo todo. Em particular, foi importante, nesse sentido, o trabalho de Pikety (2013), independentemente de quaisquer que sejam as críticas que tenham sido feitas a ele.

O ganho de importância da desigualdade como tema de análise é, de fato, recente. Como menciona Atkinson (2016), os economistas deixam de lado a distribuição ao construir e aperfeiçoar a teoria econômica. Ele chama atenção para a opinião, nesse sentido, de diferentes economistas interessados no assunto, como é o caso dele mesmo e de outros que, ao se dedicarem ao tema e buscarem inspiração na literatura econômica, pouco encontraram e, mais que isso, foram pouco valorizados como pesquisadores. De fato, a teoria econômica ortodoxa, ou o chamado mainstream em economia, cuja base é a teoria do valor-utilidade, nas suas várias versões, tem dificuldades teóricas 
para analisar esse tema como relevante. ${ }^{3}$ É isso que leva Sen $(1973$, p. 16) a dizer que o utilitarismo, ao tratar da soma das utilidades dos indivíduos, mostra-se "sumamente despreocupado com a distribuição interpessoal dessa soma. Isso deveria tornar essa abordagem particularmente inadequada para medir ou julgar a desigualdade”.

A ortodoxia econômica concebe os indivíduos como homogêneos. Ora são consumidores, ora vendedores de fatores de produção dos quais são proprietários. Independentemente de quais sejam esses fatores (capital, ou trabalho, ou recursos naturais), todos são remunerados de forma a, por um lado, compensarem o sacrifício que fazem os seus proprietários ao cedê-los para a produção. Por outro lado, a remuneração também recompensa pela contribuição marginal de cada fator à produção total. Assim, quaisquer desigualdades que daí surjam não podem ser vistas como danosas, injustas ou nefastas. É por isso que no caso dos salários baixos e do desemprego, por exemplo, a solução prevista é sempre que se amplie a qualificação, fundamental na teoria do capital humano.

Diferentes economistas fundamentais para a construção do pensamento ortodoxo justificam a desigualdade ou a tornam pouco relevante nas suas análises. É o caso, por exemplo, de Hayek (1983, p. 61), para quem "o rápido avanço econômico com que passamos a contar parece em grande medida, resultar dessa desigualdade e ser impossível sem ela”. Para ele, as diferenças são importantes para desenvolver bens e serviços novos. Por um lado, é preciso recursos para produzi-los, recursos que não existiriam se a renda fosse bem distribuída. Por outro, é preciso "o capricho dos poucos escolhidos, antes de se tornar algo desejado por todos, passando a fazer parte das necessidades da vida. Pois o luxo de hoje é a necessidade de amanhã" (1983, p. 61).

Também Lucas (2004) estabelece essa relação entre desigualdade e progresso. Para ele, "a única maneira de o aprendizado e a transferência de tecnologia ocorrerem é os produtores competirem seriamente internacionalmente” (p. 12, tradução nossa). Diz ainda que o potencial para melhoria da população mais pobre, por qualquer que seja o meio de distribuir produção, é inferior ao potencial fornecido pelo aumento dela. A razão é que a diferença entre os níveis de desenvolvimento tende a se reduzir, e os níveis de desenvolvimento a convergirem, sempre que a concorrência possa exercer seu papel. Segundo essa concepção, para crescer é preciso poupança prévia e então deixar que a concorrência, num mercado liberalizado, leve a poupança existente à busca de ganhos maiores em países ou regiões mais pobres, onde há oportunidades maiores de

3 Estamos nos referindo aqui às escolas neoclássica, novo-clássica e novo-keynesiana, que compartilham a noção de valor-utilidade e que consideram o mercado como o melhor regulador econômico a curto ou a longo prazo.

4 "(...) on the tendencies that are harmful to sound economics, the most seductive, and in my opinion the most poisonous, is to focus on questions of distribution". 
investimento e então maior rentabilidade. Além disso, se a tecnologia é melhor nas regiões e nos países desenvolvidos, garantindo maiores taxas de crescimento, "a única maneira de o aprendizado e a transferência de tecnologia ocorrerem é os produtores competirem seriamente internacionalmente"5 (LUCAS, 2004, p. 12, tradução nossa).

Trata-se, portanto, de outra razão para que a desigualdade seja difícil de ser tratada como problema na economia ortodoxa, qual seja a importância que a concorrência tem no equilíbrio dos mercados, considerados aí os melhores reguladores econômicos. É a concorrência que leva à eficiência econômica dentro desses modelos, e é preciso, então, respeitar, não apenas a desigualdade no início, que a estimula, como o seu resultado desigual, considerada justa recompensa pela maior aptidão.

Muito distintas são as posições heterodoxas sobre a concorrência e seu impacto sobre as desigualdades pessoais e regionais. Em posições que divergem da ortodoxia econômica, a concorrência que movimenta o mercado não conduz, uma vez ele deixado livre, à convergência de níveis de desenvolvimento entre países e regiões. As visões póskeynesianas, por exemplo, veem problemas para tal convergência macroeconômica de níveis de desenvolvimento entre países e regiões, relacionados à incerteza que permeia as decisões econômicas. Essa incerteza é maior nos menos desenvolvidos, em vista das rendas menores e das maiores dúvidas sobre as possibilidades de venda, além da dependência maior de exportações e importações fora de seus controles (Amado, 1997; Mollo; Amado, 2001). Essa maior incerteza leva à maior preferência pela liquidez dos potenciais investidores desses países e regiões menos desenvolvidos, inibindo investimentos e levando à migração de capitais para mercados de países e regiões mais desenvolvidos. Assim, a desigualdade cresce, ao invés de se reduzir, se o mercado for deixado livre de regulação estatal.

Além disso, no capitalismo, busca-se aumentar a produtividade do trabalho de forma a ampliar o lucro. Este aumenta porque quanto mais avançado é o método de produção, mais reduzidos são os custos individuais de produção em relação à média, que baliza os preços de mercado dos produtos. Assim, os setores e empreendimentos que utilizam tecnologia moderna têm superlucros. Tais processos, diferentemente do que pensa a ortodoxia, não levam à convergência entre os níveis de desenvolvimento, mas, conforme apontam os marxistas, tendem a concentrar capital nas mãos de poucos, aumentando a desigualdade. Conforme destacam Mollo (2015) e Mollo e Amado (2001), a concorrência se faz no capitalismo por meio de inovações tecnológicas. Mas, em primeiro lugar, a pesquisa, o desenvolvimento e a implementação de tecnologias cada vez mais modernas são processos muito caros e, por isso, tendem a ser encabeçados

\footnotetext{
5 “(...) the only way learning and technology transfer can take place is for producers to compete seriously internationally".
} 
pelos que primeiro e mais tiveram superlucros. Ora, esse é um processo que, salvo exceções que não fazem mais do que confirmar a regra, concentra capital nas mãos de poucos ou transforma a concorrência em oligopólios e monopólios. Isso, por si só, já aumenta a desigualdade no interior dos países e regiões quanto mais acirrada é a concorrência. Como os países e regiões mais desenvolvidos são os que primeiro implementaram as tecnologias de ponta, tendem a sediar os setores mais modernos e bem-sucedidos no processo de concorrência. Assim, o resultado da concorrência acirrada é também maior divergência entre níveis de desenvolvimento econômico, e não convergência, conforme esperado pela ortodoxia.

Em segundo lugar, observe-se que as tecnologias, numa sociedade cujo objetivo é o lucro e que a concorrência exige que o capitalista busque maximizá-lo, não buscam folgar o trabalhador, mas aumentar sua produtividade. Assim, a tecnologia é, em regra, poupadora de mão de obra, o que é outra maneira de aumentar a desigualdade dentro e entre países. Essa é outra razão para o aumento enorme da desigualdade nos nossos dias e de sua ampliação, como destacado por Piketty (2013) ao analisá-la evolutivamente.

Enfim, cabe destacar que a redução da desigualdade é fundamental para a construção do interesse comum, algo que pensamos ser particularmente importante. O interesse comum aqui é o da chamada vontade geral de Rousseau (2000). Para ele, a vontade geral é diferente da vontade de todos. Esta última é a do voto, e não é mais do que a soma de interesses particulares. A vontade geral é mais importante, porque significa o que interessa a todos. Esse é o interesse comum aqui explorado.

Para Rousseau (1754, p. 36), "concorrência e rivalidade de uma parte, e, de outra, oposição de interesses, e sempre o desejo oculto de tirar proveito à custa de outrem: todos esses males constituem o primeiro efeito da propriedade e o cortejo inseparável da desigualdade nascente". Quanto mais próximas forem as condições de vida do homem, maior será então seu interesse comum. Assim, importa colocar os homens em maiores condições de igualdade, de forma a construir interesses comuns. $\mathrm{Ou}$, dito de outra forma, é a igualdade de interesses particulares que garante o interesse comum ou o interesse universal, o que requer menor desigualdade de condições de vida em geral. Quaisquer tentativas de redução da desigualdade, porém, nas nossas economias, requerem políticas públicas que compensem as consequências da concorrência no mercado, razão pela qual buscamos um índice que instrua melhor tais políticas.

\section{A QUESTÃO DA DESIGUALDADE MULTIDIMENSIONAL}

O caráter mercantil das economias capitalistas faz de todos compradores e vendedores para garantirem suas existências, razão pela qual o nível de renda é fundamental para 
medir a desigualdade. Rowntree (1901), Orshansky (1965) e os trabalhos posteriores preocupados em medir a pobreza encontraram na insuficiência da renda a privação do indivíduo racional, dado que, dispondo de renda, o indivíduo eliminaria automaticamente todas as suas privações na sequência correta das suas prioridades (COMIM; BAGOLIN, 2002; MONTEIRO, 1995; SALAHUDDIN; ZAMA, 2012). Soma-se a esse argumento a compreensão de que a renda é um importante determinante para o nível de consumo, e por ser capaz de garantir as necessidades mais básicas do indivíduo, compõe uma boa proxy na mensuração da carência (COBO; ATHIAS; MATTOS, 2013; LAVINAS, 2010).

A síntese das críticas sobre considerar a privação do indivíduo apenas do ponto de vista unidimensional pode ser estruturada em cinco argumentos: i) a renda, ou qualquer outra variável, mesmo sendo uma boa proxy para as escolhas humanas, não corresponde a uma variável suficiente em si para este exercício; ii) no caso da renda, essa variável deve ser tratada como um meio, o seu dispêndio não estando necessariamente vinculado ao "bem-estar" da sociedade; iii) o nível de vida pode ser superior ao permitido pela variável de corte quando a unidade de observação for capaz de compartilhar o consumo com outras unidades; iv) diante de racionamentos, por exemplo, a posse da renda não é suficiente para suprir suas necessidades básicas; v) esse método reduz a análise da privação do indivíduo a critérios que simplificam a classificação da pobreza, dado que outros elementos devem auxiliar nessa definição (ATKINSON, 2008; DUCLOS e ARAAR, 2006; SALAHUDDIN; ZAMAN, 2012). Portanto, optar pela renda para a determinação da privação deixa de captar as oscilações efetivas e complexas do "bemestar”. Mesmo quando o indivíduo é racional e sofre de privação, a renda não é despendida de forma eficiente pela ordem da prioridade. Estudos empíricos mostraram que, nessas situações, gastos com vícios e outros itens não essenciais compõem a cesta familiar (SALAHUDDIN; ZAMAN, 2012).

Além desses, sabemos que existem numerosos itens que tornam a renda disponível maior ou menor, assim como outros que permitem reduzir ou aumentar tal desigualdade ao longo do tempo, seja do ponto de vista individual ou coletivo, reduzindo ou aumentando as possibilidades de mudanças sociais. No agregado, essas são razões por si sós suficientes para contemplar a desigualdade do ponto de vista multidimensional.

A elevação da posse de ativos (físicos, humanos e sociais) assume um papel de destaque ao permitir que tais famílias usufruam deles, da capacidade de aumentar a geração de renda e de condições mais favoráveis diante de choques adversos da renda (NERI, 2000). Assim, as necessidades básicas deixam de depender exclusivamente da renda, já que a insatisfação também é consequência da carência desses ativos. Portanto, a renda é relevante até o ponto em que não prive o indivíduo de gerar o nível adequado de capacidades. Admitindo $n+1$ dimensões, a unidade de observação pode ser privada em um, mas não em outros aspectos, embora particularmente haja situações graves em 
que sofre privações em várias dimensões, o que normalmente é referido na literatura como "carências múltiplas" (ATKINSON, 2008).

Daí porque mais recentemente o debate acadêmico tem convergido para o reconhecimento da necessidade de uma gama de variáveis para qualificar o padrão de vida dos indivíduos, ou para analisar a desigualdade entre eles. A noção de desigualdade unidimensional está sustentada no argumento de que o padrão de vida é reflexo da posse de bens e serviços, que dependem dos rendimentos. A renda per capita figura, assim, como uma medida primária (EASTERLIN, 2000). Porém, a constatação da necessidade de incorporar outros elementos levou ao crescimento dos estudos em torno da desigualdade multidimensional, cujos trabalhos inaugurais são os capítulos seminais de Kolm (1977) e Atkinson e Bourguignon (1982) (WEYMARK, 2004).

O estudo multidimensional permite captar a heterogeneidade da desigualdade, tendo ciência de que o indivíduo se preocupa com outros fatores, por exemplo, a saúde e a educação (DECANCQ, 2011; SIAL; NOREEN; AWAN, 2015). Nesse caso, a renda, ou despesa, desempenharia um papel de certa forma grosseiro ou rudimentar quanto à qualidade de vida desfrutada pelo indivíduo (AABERGE; BRANDOLINI, 2014). Em um relatório recente da Comissão sobre Medição de Desempenho Econômico e Progresso Social, Stiglitz, Sen e Fitoussi (2009) abordaram a necessidade do levantamento dos determinantes do bem-estar numa perspectiva multidimensional. Sobre a pesquisa acadêmica e uma série de iniciativas concretas desenvolvidas em todo o mundo, a Comissão identificou as seguintes dimensões-chave, que devem ser levadas em consideração, pelo menos a princípio, simultaneamente: i) padrão de vida material (renda, consumo e riqueza); ii) saúde; iii) educação; iv) atividades pessoais, incluindo trabalho; v) voz política e governança; vi) conexões e relacionamentos sociais; vii) ambiente (condições presentes e futuras); viii) insegurança, de natureza econômica e física. Todas essas dimensões dão forma ao padrão de vida das pessoas e, no entanto, muitas delas são perdidas por medidas de renda convencionais.

Em uma pesquisa de grande escala entre os pobres globais realizada pelo Banco Mundial, documenta-se que os próprios pobres também concebem a privação como uma noção multifacetada, com dimensões materiais e psicológicas (NARAYAN, 2000). Além disso, a literatura emergente sobre os determinantes da felicidade e a satisfação da vida mostram que a satisfação geral das pessoas é considerada por meio de diversos aspectos da vida, como a saúde, o emprego, os recursos materiais e o estado civil (KAHNEMAN; KRUEGER, 2006).

Nesse contexto, cumpre, inicialmente, fazer a seleção das dimensões ou atributos relevantes na construção do indicador utilizado para a mensuração. Apesar de ainda incipientes e não consensuais, as dimensões e os indicadores são comumente debatidos levando em conta, em primeiro lugar, a importância a eles atribuída na definição de 
desigualdade econômica e, em segundo lugar, a sua disponibilidade. Os critérios utilizados para a seleção dos atributos ou variáveis a se contemplar levam em conta, em terceiro lugar, a satisfação de algumas das propriedades básicas quanto à possibilidade de mensuração (AABERGE; BRANDOLINI, 2014; DECANCQ; DECOSTER; SCHOKKAERT, 2006; EASTERLIN, 2000; LUGO, 2005; Schokkaert, 2007).

No Brasil, estudos sobre a desigualdade multidimensional esbarram no formato, ausência e frequência da disponibilidade de dados. A própria complexidade na definição das dimensões de interesse reflete-se na demanda por variáveis que permitam captá-las, o que, mesmo em países com referência na coleta e disponibilidade de dados, apresenta-se como gargalos para a construção de indicadores multidimensionais. Assim, frequentemente, para esse tipo de abordagem, há dificuldades de estimação e faz-se necessário ajustar a escolha das dimensões e indicadores de acordo com a finalidade da mensuração (DEDECCA, 2013; SILVA; PINHO; SILVA, 2020). As principais bases de dados amostrais no Brasil requerem a cautela do cientista, inclusive na abordagem unidimensional, em: i) considerar os efeitos do plano amostral complexo nos respectivos estudos; ii) considerar a possibilidade de subestimação do nível de rendimento e a participação em programas sociais; iii) perceber a ausência dos rendimentos não monetários, como os subsídios, e aqueles que dizem respeito à composição do rendimento na forma de ações e títulos, aplicações financeiras e lucros retidos derivados de participação societária; iv) contemplar dados patrimoniais; v) atentar para a carência de dados das dimensões sociais cuja oferta se dá na forma de bens e serviços públicos de uso coletivo, como é o caso de saúde, cultura, lazer, segurança e outros (BATISTA, 2018; MEDEIROS; SOUZA; CASTRO, 2015; SILVA; PESSOA; LILA, 2002; SILVEIRA et al., 2013; SOUZA, 2015; TROVÃO, 2015).

Partindo dessas considerações, os índices aqui sugeridos permitem analisar a distribuição conjunta das privações, o que requer que os dados sejam provenientes de uma única fonte, já que tomam o indivíduo como unidade de observação. Assim, é possível selecionar o número de privações, bem como a equidade do respectivo usufruto dos bens e serviços selecionados. Adicionalmente, esse tipo de medida escalar possibilita o ordenamento no tempo e no espaço dos resultados encontrados (FERREIRA; LUGO, 2013).

A proposta de um indicador, bem como das dimensões que o compõem, envolve sempre algum grau de subjetividade, não sendo jamais neutra (JANNUZZI, 2002; LUGO, 2005). Por isso, ao sintetizar várias dimensões empíricas da realidade do indivíduo, é inevitável que sejam gerados questionamentos em torno da proposta dada (RYTEN, 2000).

A partir da revisão de literatura realizada neste trabalho, conclui-se que a escolha das dimensões ou atributos dependem: da sua importância para expressar a incapacidade do indivíduo de se realizar nas esferas da vida privada e social; da disponibilidade de dados e da possibilidade de mensuração. Tendo isso em mente, tomamos como base a Pesquisa Nacional por Amostra de Domicílios (PNAD), contemplando os indivíduos 
como unidade de observação para instruir as políticas públicas, e sugerimos algumas dimensões para a construção do índice multidimensional.

A PNAD é a fonte de dados mais usada nas análises sobre pobreza no Brasil (SERRA; YALONETZKY; BELIK, 2017). Aqui, chama-se atenção para o fato de as dimensões e as bases de dados utilizadas para a pobreza guardarem semelhança com as da desigualdade (BATISTA, 2018; SOUZA, 2015). Entretanto, cabe ressaltar que o Brasil dispõe de outras fontes de dados secundários, sendo as principais o Censo Demográfico (Censo) e a Pesquisa de Orçamentos Familiares (POF). Embora essas duas possam apresentar níveis mais desagregados para uma dada dimensão, ou mesmo obter outras dimensões que não estão disponíveis na PNAD, o Censo e a POF carecem de microdados atuais. No caso do Censo, cita-se ainda as mudanças nos seus questionários (NERI, 2011). Ainda segundo Neri (2011), a constância do questionário da PNAD desde 1992 é outro importante elemento quando se trata da formação de séries históricas. Aqui menciona-se a Pesquisa Nacional por Amostra de Domicílios Contínua (PNAD-C), que apesar de ser uma pesquisa diferente da PNAD (IBGE, 2017), guarda variáveis semelhantes, conforme especificações do dicionário da pesquisa. Por fim, mencionamos o trabalho de Souza (2015), que estabelece um paralelo entre POF, PNAD e Censo após a harmonização ex post dessas pesquisas, apresentando a convergência dos resultados sobre a pobreza e desigualdade no Brasil. Entretanto, a pesquisa foi realizada do ponto de vista unidimensional. A revisão da literatura realizada neste trabalho não encontrou outras referências para as demais variáveis socioeconômicas. Por outro lado, pode-se afirmar, segundo Souza (2015, p. 185), que "nenhuma pesquisa jamais será capaz de retratar com perfeição o que é o 'mundo real'. O importante é entender os limites de cada pesquisa e quão compatíveis entre si elas são [...] o retrato que emerge do Brasil nos censos, nas PNADs e nas POFs é coerente e robusto". Essas são as razões pelas quais a PNAD foi a contemplada na nossa sugestão. Cabe ver Jannuzzi (2017), que faz um levantamento da disponibilidade de dados para criação de indicadores sociais.

A proposta deste trabalho é a construção de índices normativos e não há consenso de quais variáveis devem compor as dimensões destes, como se constata nas publicações nacionais e internacionais sobre o tema. Visando a objetividade na seleção dessas dimensões e tomando as especificidades das fontes secundárias de dados no Brasil, além de buscar contemplar as esferas de interesse apresentadas por Stiglitz, Sen e Fitoussi (2009), apresentamos as variáveis normalmente utilizadas quando se trata das dimensões que captam as privações múltiplas dos indivíduos ou domicílios, para inferir a satisfação dos indivíduos. Isso pode ser observado nos trabalhos de Barros, Carvalho e Franco (2006); Cobo, Athias e Mattos (2013); Lugo (2005); Serra, Yalonetzky e Belik (2017); Silva, Pinho e Silva (2020), e Vaz (2013). Por fim, cabe mencionar que tais 
dimensões são passíveis de alteração a depender do interesse do pesquisador e trata-se, portanto, de uma proposta e exemplificação da sua factibilidade.

O formulador deve estar ciente da complexidade da seleção dessas dimensões para que se aproxime do equilíbrio entre abrangência e objetividade na formulação ou caracterização da problemática social (JANNUZZI, 2017). Para Heroit (1970), na seleção das dimensões consideradas para a formulação do indicador social, é desejável que elas descrevam a realidade a partir de dados objetivos e comparáveis e/ou critérios considerados socialmente relevantes. Nesse sentido, Jannuzzi (2002) elenca uma série de qualidades desejáveis para os indicadores sociais, como: relevância; validade para indicar o conceito em análise; confiabilidade dos dados usados; grau adequado de cobertura populacional para os propósitos; sensibilidade às políticas públicas implementadas; especificidade a efeitos de programas setoriais; inteligibilidade para agentes e públicos-alvo das políticas; possibilidade de atualização a custos acessíveis; possibilidade de desagregação geográfica, sociodemográfica e socioeconômica; e capacidade de comparação no tempo. Reconhece, porém, a dificuldade de encontrar nos indicadores todas essas qualidades.

A dimensão econômica, relativa aos rendimentos monetários stricto sensu - ligados à obtenção de renda (medida primária) - que, dentre o leque de opções, podem ser constituídos da renda monetária I, rendimento mensal do indivíduo no trabalho principal e a renda monetária II, constituída do rendimento mensal do indivíduo de outras fontes que não o trabalho principal. ${ }^{6}$

A dimensão bens de consumo pode englobar a posse de aparelhos domésticos e eletrônicos que, respectivamente, correspondem a itens básicos para o funcionamento do domicílio e para o acesso a informações. ${ }^{7}$ É preciso evitar, todavia, que a escolha dos bens não comprometa o resultado final, no sentido de envolver supostos sobre o que se quer demonstrar.

A seguridade social também é relevante nesse debate ao captar a proporção de pessoas situadas no mercado de trabalho em melhor situação (por exemplo, maiores de 15 anos que trabalham e têm carteira assinada no período de referência).

6 Aqui estão incluídas a renda proveniente de aposentadorias e programas de transferência de renda, por exemplo, que são relevantes para estudos sobre pobreza e desigualdade. Inclusive, na PNAD existem técnicas que permitem desagregar os ganhos do Programa Bolsa Família, por exemplo. Como o nível de desagregação da renda está condicionado ao interesse do pesquisador, é possível discriminá-la em outras variáveis. Ver Medeiros, Souza e Castro (2015) para compreender a relevância da desigualdade em outros rendimentos, além do trabalho principal, dadas as especificidades socioeconômicas brasileira.

7 A desagregação de bens de consumo está de acordo com Campello et al. (2018), que leva em conta a realidade brasileira. Entretanto, novamente, de acordo com o interesse do pesquisador e o objetivo da pesquisa, a PNAD oferece uma variedade de outras combinações e desagregações para essa dimensão. 
As condições sanitárias podem ser captadas pelas variáveis que permitem distinguir se a população tem acesso a água encanada, rede de esgoto ou fossa séptica e destino adequado ao lixo.

Uma quinta proposta relaciona-se com a dimensão da educação. É possível captar a proporção da população, fazendo recortes por idade, que tenha concluído os diferentes graus de escolaridade. Por exemplo, adultos com ensino médio completo e jovens com ensino fundamental completo.

Por fim, a participação social é contemplada pela proporção da população que estuda em escola pública. ${ }^{8}$ Neste artigo, a ideia é a de que quanto maior for a participação do indivíduo na sociedade, maiores serão suas possibilidades de interferir na solução de seus problemas. Mas além disso, quanto maior for a participação da sociedade como um todo nas mesmas atividades sociais, dispondo e compartilhando dos mesmos atributos, maior tenderá a ser o interesse comum e a solução coletiva de problemas, conforme discutido anteriormente.

Cabe ainda ressaltar a "participação social" enquanto uma dimensão que vem sendo destacada em diferentes estudos. Como menciona Suppa (2017), esta é uma preocupação de diferentes autores na análise da pobreza (Gordon; Pantazis, 1997; Mack; Lansley, 1985; SeN, 1983; Townsend, 1979). Esses autores consideram a pobreza e desigualdade impedindo ou privando os indivíduos de alcançarem ou acessarem a participação social. A participação social é então vista como requisito para a capacitação do indivíduo, melhorando as condições de obtenção de suporte ou ajuda social. Aqui, cabe ressaltar a relevância do acesso a serviços fornecidos pelo setor público, como educação e saúde, para melhorar a participação social do indivíduo e sua satisfação individual (CAMPELLO et al., 2018). Nesse sentido, os gastos sociais são importantes (SILVEIRA; PASSOS; GUEDES, 2018), já que têm efeito direto sobre a desigualdade de renda e, ao prover acesso a outros bens e serviços (por exemplo, saúde e educação), também contempla outras dimensões relevantes para os indivíduos dentro da abordagem multidimensional da desigualdade. Ou seja, a oferta pública de bens e serviços, em particular a famílias de menor poder aquisitivo, reflete-se na melhoria da sua qualidade de vida (SILVEIRA, 2008). ${ }^{9}$

8 O ideal seria contemplar neste indicador não apenas a educação pública, mas saúde, transporte e lazer públicos, mas não existem dados disponíveis.

9 Assim como para a estruturação e definição das dimensões de interesse para construir índices multidimensionais de desigualdade, captar do ponto de vista tributário os impactos distributivos do gasto social, além da saúde e educação, também encontra uma série de barreiras quanto à necessidade de ajustes e tratamentos dos dados, bem como no que tange à sua inexistência (SILVEIRA, 2008). A título de exemplo, pode-se mencionar as políticas de saneamento básico, financiamento à habitação e transporte público. Nesse contexto, ver Silveira (2008) e Silveira, Passos e Guedes (2018), que abordam essas dificuldades na disponibilidade de dados e, para casos específicos, mencionam soluções para superá-los. 
Nessa cesta de sugestões de dimensões e indicadores, visando levantar as características do público-alvo, uma gama de outras variáveis que permitem captar as condições sociais pode ser contemplada: a fragilidade econômica local e regional, o nível de participação da sociedade, indicadores demográficos, condições ambientais, além de outros que permitam subsidiar diagnósticos abrangentes do contexto da região analisada, bem como dimensionar a demanda social (JANNUZZI, 2018). Elas devem estar voltadas para dar sustentação a políticas e programas socioeconômicos, atentando para estarem de acordo com seus próprios objetivos, com a natureza do programa, o público-alvo e as questões sociais em pauta (JANNUZZI, 2002, 2018). Além disso, deve-se ter em mente que diferentes escolhas de variáveis levam a diferentes resultados, razão pela qual diferentes índices de desigualdade e de pobreza multidimensionais podem gerar resultados distintos para uma mesma amostra e período analisados (DECANCQ; DECOSTER; SCHOKKAERT, 2006; LUGO, 2005; JANNUZZI, 2002). Isso mostra a importância do debate para a construção de um índice, buscando garantir que o conceito abordado sustente a argumentação e os indicadores propostos (JANNUZZI, 2002).

$O$ índice multidimensional é uma medida quantitativa que visa operacionalizar um conceito social abstrato, mas dotado de conteúdo teórico. A sua construção não é isenta de valores ideológicos e políticos, por isso é dotado de orientações teóricas e opções metodológicas dos seus proponentes (JANNUZZI, 2002). Daí a ausência, neste artigo, de uma proposta acabada em termos de dimensões e variáveis a examinar. As discussões teórico-metodológicas envolvendo a escolha das dimensões e dos indicadores demandariam outro artigo. As dimensões levantadas anteriormente são apenas algumas das possibilidades disponíveis na PNAD que são sensíveis na transição e vulnerabilidade da situação do indivíduo na sociedade (CAMPELLO et al., 2018), não sendo possível no escopo deste artigo aprofundar mais a discussão sobre elas. O mesmo tipo de limitação encontramos sobre os pesos a serem atribuídos a cada dimensão.

O debate em torno dos pesos, de acordo com Decancq (2009) e Decancq e Lugo (2010), esbarra não apenas nessa questão subjetiva dos formuladores como em impasses matemáticos, o que faz da estrutura de pesos bastante debatida e sem consenso. A arbitrariedade na seleção dos pesos é, portanto, passível de questionamentos na proposta de indicadores (GUIMARÃES; JANNUZZI, 2004).

Em suma, a estrutura de pesos atribuída a cada dimensão deve expressar a relevância de cada atributo para a satisfação da unidade de observação, e deve atentar para o objetivo da política pública que se quer informar; além disso, os pesos são cruciais para captar a percepção das unidades de observação em pior situação, bem como para estabelecer paralelos entre elas (DECANCQ, 2013 apud AABERG; BRANDOLINI, 2014). A seleção ideal dos pesos poderia ser obtida via relevância dos atributos segundo avaliações dos legisladores ou unidades de observação. Isso se configura, porém, 
uma tarefa árdua, inclusive diante da necessidade de transportar as avaliações para os dados e de algum consenso. Por essas e outras dificuldades metodológicas, comumente atribui-se em geral pesos iguais para os atributos (MAYER; JENCKS, 1989 apud AABERG; BRANDOLINI, 2014; AABERG; BRANDOLINI, 2014). ${ }^{10}$

\section{A ABORDAGEM MULTIDIMENSIONAL: ATRIBUTO POR ATRIBUTO E ÍNDICE AGREGADO}

Após a determinação das dimensões ou atributos relevantes, cabe descrever e analisar o duplo modo de tratar a abordagem multidimensional da desigualdade: forma agregada e forma desagregada. Na primeira, é gerado um índice que capta a evolução global da desigualdade, enquanto na segunda, os atributos que compõem a desigualdade são analisados separadamente, o que permite discernir a flutuação dos determinantes do bem-estar da qualidade de vida do indivíduo.

Seja $k=[1,2, \ldots, K]$ o conjunto de atributos; $i=[1,2, \ldots, N]$ o conjunto de unidades de observação (indivíduos, famílias, unidades da federação etc.), com n > 1; e $M(N)$ o conjunto das matrizes $N \times K$ com elementos não negativos. A distribuição multidimensional é dada pela matriz $X \in M(N)$, em que $x_{n k} \in \mathbb{R}_{+} \forall n, k$. Temos então que:

$$
X=\left[\begin{array}{cccc}
x_{11} & x_{12} & \cdots & x_{1 K} \\
\vdots & \vdots & \ddots & \vdots \\
x_{N 1} & x_{N 2} & \cdots & x_{N K}
\end{array}\right] ; k=[1,2, \ldots, K] ; \mathrm{i}=[1,2, \ldots, N]
$$

onde $x_{k n}$ é a realização do $n^{a}$ unidade de observação na $k^{a}$ dimensão, o que permite denotar $x_{n^{*}}=\left(x_{n 1}, \ldots, x_{n K}\right) \forall n$ como o vetor linha de realizações para a $n^{a}$ unidade de observação e; $x_{* k}=\left(x_{1 k}, \ldots, x_{N k}\right) \forall d$, que representa o vetor coluna de realizações para o atributo $k^{a}$.

A desigualdade multidimensional atributo por atributo é captada por $x_{* k}=\left(x_{1 k}, \ldots, x_{N k}\right) \forall d$, que permite gerar informações sobre a realização da unidade de observação para determinado atributo. Partindo da abordagem normativa da desigualdade iniciada por Atkinson (1970), adota-se uma função para especificar o pacote de realização da unidade de observação. Ou seja, tomando ciência da realização do indivíduo

\footnotetext{
10 As vias para a atribuição dos pesos são: direta, que consiste na entrevista da opinião do público geral; e indireta, por meio de estimativas de equações de felicidades. Há duas abordagens para atribuição dos pesos: a baseada em frequência, que atribui maior peso aos atributos de menor frequência de privação; e técnicas estatísticas multivariadas (AABERG; BRANDOLINI, 2014). Ver Decancq (2009), Lugo (2005) e AAberg e Brandolini (2014) sobre a complexidade na determinação dos pesos.
} 
condicionada a um grupo de variáveis, é possível estruturar, a partir da matriz de distribuição $X$, equação (1), um “pacote de variáveis” que traduz a satisfação ou realização do indivíduo, tal que: $S_{\xi}(X): X \mapsto \mathbb{R}$. Trata-se de uma função com média ponderada de ordem $\xi$ das realizações nos $k$ atributos selecionados (ARISTEI; BRACALENTE, 2011; MAASOUMI, 1986).

Na sequência, torna-se possível gerar uma função que capta a desigualdade dessas realizações. Para isso, admite-se a validade do Princípio Pigou-Dalton (DECANCQ, DECOSTER e SCHOKKAERT, 2006), que satisfaz a situação em que a transferência da realização em $S_{\xi}\left(x_{i}\right)$ da unidade de observação mais realizada em termos dos atributos para o menos favorecido resultaria no acréscimo global da realização da amostra e, paralelamente, na redução da desigualdade (ARISTEI; BRACALENTE, 2011; LUGO, 2005; WEYMARK, 2004).

\subsection{ANÁLISE ATRIBUTO POR ATRIBUTO}

Como apresentado, a desigualdade multidimensional atributo por atributo é captada por $x_{* k}=\left(x_{1 k}, \ldots, x_{N k}\right) \forall d$, que permite gerar informações sobre a realização da unidade de observação para determinado atributo. Tomando uma função que permite captar a realização da amostra para um dado atributo válida para todo $x_{i} \epsilon X$, como: ${ }^{11}$

$$
S\left(x_{i}\right)=\left[\frac{1}{n} \sum_{i=1}^{n} x_{i}^{1-\varepsilon}\right]^{1-\varepsilon}
$$

Aqui, $\varepsilon \in \mathbb{R}_{+}$quantifica a aversão social à desigualdade, tal que se $\varepsilon=0$, a sociedade não tem aversão à desigualdade, ou seja, a sociedade seria indiferente à transferência de atributos entre as unidades de observação. Se $\varepsilon>0$ implica na aceitação do princípio de transferência de Pigou-Dalton e se $\varepsilon \rightarrow \infty$, então com a aversão à desigualdade ao máximo, a análise tende a se concentrar em mudanças nos grupos de unidades de observação que gozam de menos atributos. No caso de políticas públicas, e em vista da importância atribuída à redução da desigualdade para a construção do interesse comum, essa hipótese é a melhor escolha.

Feita essa definição, torna-se possível estabelecer uma função aditiva separável do bem-estar definido por $W(X)$, expressa como:

$$
W(\mathcal{X})=\frac{1}{1-\varepsilon} \sum_{i=1}^{n}\left[S\left(\mathcal{X}_{i}\right)\right]^{1-\varepsilon}
$$

\footnotetext{
${ }^{11}$ A função selecionada está de acordo com a apresentação de Decancq, Decoster e Schokkaert (2006).
} 
Então, o Índice de Desigualdade Unidimensional de Atkinson-Kolm-Sen (AKS), $I^{U}(X)$, é a solução de: ${ }^{12}$

$$
\mathrm{W}\left[\left(1-I^{U}(X)\right) \mu(S)\right]=W(X)
$$

em que $\mu(S)$ é a realização média entre as unidades de observação. Portanto, $I^{U}(X)$ é o escalar, cujo valor seria igual a zero se a realização em todos os atributos fosse igual entre as unidades de observação. Logo, é possível mensurar a perda no bem-estar decorrente da desigualdade via acréscimos em $I^{U}(X)$ :

$$
I^{U}(X)=1-\left[\frac{1}{n} \sum_{i=1}^{N}\left[\left(\left[\frac{\left.S\left(X_{i}\right)\right]}{\mu(S)}\right)^{1-\varepsilon}\right]\right]^{\frac{1}{1-\varepsilon}} ; k=1, \ldots, K\right.
$$

Em termos de média generalizada, a equação (5) deve ser reescrita como:

$$
I^{U}(x)=1-\frac{\mu_{1-\varepsilon}\left(\mu\left(x_{i}\right)\right)}{\mu\left(\mu\left(x_{i}\right)\right)}
$$

Adaptando a equação (5) para captar a dimensão de interesse:

$$
I^{U}\left(x_{* k}\right)=1-\left[\frac{1}{n} \sum_{i=1}^{N}\left[\left(\frac{x_{i k}}{\mu\left(x_{k}\right)}\right)^{1-\varepsilon}\right]\right]^{\frac{1}{1-\varepsilon}} ; k=1, \ldots, K
$$

A justificativa para a análise desagregada consiste, principalmente, em lançar luz sobre o movimento da desigualdade global constituído por múltiplas causas, bem como sua possibilidade de comparação evolutiva entre as dimensões (DECANCQ; DECOSTER; SCHOKKAERT, 2006; PHAN, 2016). Além disso, ao gerar informações mais detalhadas, cria-se um cenário mais rico em informações para as políticas públicas, no sentido de ampliar o leque de possibilidades de sua atuação (EASTERLIN, 2000).

Cabe ressaltar alguns trabalhos que analisaram a desigualdade multidimensional desagregada. O comum entre eles é o estudo empírico entre países, e não dos países; além disso, os trabalhos buscam analisar a convergência multidimensional. As controvérsias

12 Abordagem inspirada nas teorias da desigualdade de Atkinson, em 1970, Sen, em 1973, e Kolm, em 1976, chamada método AKS (PHAN, 2016). 
sobre os resultados estão associadas, basicamente, à ausência de dados passíveis de comparação entre países e às diferenças de metodologia, parâmetros e dimensões adotados (DECANCQ, 2011). A título de exemplo, Easterlin (2000) constatou que hoje as condições humanas, numa perspectiva multidimensional, são melhores, destacando a velocidade relativa dessas mudanças positivas em países menos desenvolvidos, a respeito da experiência histórica da Europa Ocidental. O autor ainda sublinha a notável desigualdade dos atributos nas extremidades; de um lado a Europa Ocidental, de outro a África Subsaariana. Neumayer (2003) também observou a convergência no padrão de vida nos países analisados e as atribuiu às melhorias no desenvolvimento socioeconômico assistidas no último século. Hobijn e Franses (2001) destacam que a convergência da renda, mensurada pelo Produto Interno Bruto (PIB) per capita, não implica a convergência dos demais atributos sociais. $\mathrm{Na}$ análise qualitativa, ainda se pode afirmar a existência de desigualdade multidimensional considerável entre países ricos e pobres quando se incluem as variáveis sociais. Decancq, Decoster e Schokkaert (2006), analisando as dimensões que compõem o Índice de Desenvolvimento Humano (IDH), educação, saúde e renda, observaram que a desigualdade de renda não ponderada aumenta ao longo do tempo, mas quando logaritimizada apresenta comportamento semelhante ao da expectativa de vida: mostra um padrão U, reduzindo e depois passando a crescer; já os indicadores educacionais mostram uma forte queda na desigualdade. Decancq (2011), também utilizando as dimensões que compõem o IDH, apresentou dois resultados da desigualdade para um grupo de países entre 1980-2010, ponderando e não ponderando pela população. Quando ponderada, a desigualdade para os três atributos apresentou trajetória decrescente, quando não ponderada, somente a educação apresentou clara redução, enquanto a renda apresentou trajetória crescente pós-2008, e a saúde pós-2000.

Os resultados da mensuração da desigualdade permitem lançar luz sobre o movimento da desigualdade constituído por múltiplas causas, bem como comparar a evolução das várias dimensões (DECANCQ; DECOSTER; SCHOKKAERT, 2006; PHAN, 2016).

Abordar a questão da convergência é relevante e torna insuficiente uma análise absoluta do comportamento das variáveis no tempo (EASTERLIN, 2001; NEUMAYER, 2003), porque a performance relativa é importante para a satisfação dos indivíduos, ou segundo Neumayer (2003, p. 4), "[...] People want to see their income levels and living standards improving, but also converging to those of the better off'. Esse argumento está inserido no contexto histórico dos últimos quarenta anos, marcados pelo movimento de convergência das capacidades humanas, apesar do decréscimo da velocidade, e pela inflexão deste movimento nos dias atuais, conforme constatado em alguns trabalhos (DECANCQ; DECOSTER; SCHOKKAERT, 2006; HOBIJN; FRANSES, 2001).

Neste trabalho, não é a perspectiva individual que importa, mas a efetividade das políticas públicas em tornar a sociedade mais justa, quando mais igualitária e, assim, 
ampliar o interesse comum. Ao ter ciência da flutuação da desigualdade, torna-se possível tirar conclusões e fazer prescrições mais adequadas de políticas públicas, buscando reduzir as desigualdades locais, regionais e nacionais.

\subsection{ANÁLISE AGREGADA: O ÍNDICE GLOBAL DE DESIGUALDADE}

$\mathrm{O}$ indicador composto de bem-estar associado à aplicação de um índice de desigualdade univariado (equação 5) não é suficiente para captar completamente a natureza multidimensional do bem-estar. Tendo isso em vista, uma segunda abordagem proposta pela literatura é derivar os índices multidimensionais de desigualdade de tal forma que satisfaçam algumas propriedades desejáveis e sejam diretamente aplicados aos vetores de atributos (ARISTEI; BRACALENTE, 2011). Partindo dos critérios de majoração, Majoração Uniforme (UM) e Correlação Crescente de Majoração (CIM), torna-se factível a mensuração multidimensional da desigualdade (DECANCQ; DECOSTER; SCHOKKAERT, 2006).

Estes critérios de majoração, ou dominância, são abordados em conjunto com outras propriedades desejadas, a fim de permitir que $\mathrm{I}^{\mathrm{n}}(\mathrm{X})$ estabeleça ordens parciais que, partindo do grau de desigualdade observado ou da propriedade distributiva adotada, permita a classificação da distribuição dos atributos entre as unidades de observação. Esses critérios são generalizações multiatributos do princípio de transferência Pigou-Dalton. UM mensura a dispersão dos atributos com o índice de desigualdade multidimensional, não explicando a dependência entre as dimensões, o que foi formalizado, posteriormente, por Tsui (1999) com o critério CIM. ${ }^{13}$

O índice multidimensional a ser estruturado é uma função da matriz de distribuição $X$ que agrega as diferentes variáveis: $I^{n}(X)=\mathfrak{M}(N) \mapsto \mathbb{R} .{ }^{14}$

O bem-estar ou privação da unidade de observação, $S_{\beta}$, pode ser definido como a média ponderada de ordem $\beta$ das realizações nos $k$ atributos selecionados nos "pacotes" de bem-estar das unidades de observação para o conjunto de números reais, tal que $S_{\beta}(X): X \mapsto \mathbb{R}$ (ARISTEI; BRACALENTE, 2011; MAASOUMI, 1986):

13 Sobre as propriedades do índice de desigualdade multidimensional, ver Aristei e Bracalente (2011).

${ }^{14}$ Os índices multidimensionais devem satisfazer propriedades derivadas das suas contrapartes unidimensionais e propriedades distributivas que são generalizações multiatributos do princípio de transferência Pigou-Dalton. Ver Lugo (2005), Seth (2009) e Weymark (2004). 


$$
S_{\beta}\left(x_{i}\right)=\left\{\begin{array}{c}
{\left[\sum_{k=1}^{K} w_{k} x_{i k}^{\beta}\right]^{1 / \beta} \beta \neq 0} \\
\prod_{k=1}^{K} x_{i k}^{w_{k}} \quad \beta=0
\end{array} ; i=1, \ldots, N\right.
$$

onde $x_{k} \in \mathbb{R}_{+}$representa a realização no atributo $k, w_{k} \in \mathbb{R}_{+}$, corresponde ao peso do atributo $k$ e $\beta$ é o parâmetro que determina o grau de substituição entre cada par de atributos. O valor assumido pelo parâmetro $\beta$ vai determinar, portanto, o grau de substituição entre os atributos. Se $\beta=1$, o bem-estar é a média aritmética ponderada das realizações em todos os atributos que são perfeitamente substituíveis; então, uma má performance no usufruto de um atributo pode ser compensada, em termos de bem-estar, pela melhor performance em outro. Se $\beta \mapsto-\infty$, os atributos tornam-se complementos perfeitos, e o nível do bemestar passa a depender da maior ou menor realização igual entre as dimensões. Se $\beta=0$, a função de agregação social assume a as propriedades de uma função do tipo Cobb-Douglas.

Supondo preferências homogêneas entre as unidades de observação, o índice multidimensional em dois estágios pode ser estimado dentro da abordagem normativa por meio de uma função de bem-estar social aditiva separável, como na equação (9) (DECANCQ, 2009; WEYMARK, 2004). A partir da equação (12), é possível estruturar a função multidimensional do bem-estar social como na equação (10).

$$
\begin{gathered}
W(X)=\frac{1}{1-\varepsilon} \sum_{i=1}^{N}\left[S_{\beta}\left(X_{i}\right)\right]^{1-\varepsilon} \\
W\left[\left(1-I^{M}(X)\right) Z_{\mu}\right]=W(X)
\end{gathered}
$$

A medida multidimensional da desigualdade é dada por $I^{M}(X)$, que corresponde à generalização multidimensional da definição unidimensional de AKS; em que $X_{\mu}$ é uma matriz de distribuição média onde cada observação é substituída por sua coluna média. Se todas os atributos fossem distribuídos de forma igualitária $I^{M}(X)$, assumiria valor igual a zero.

Então, definindo $\mu$ como um vetor da coluna média de $X$, e $S_{\beta}(\mu)$ como o indicador composto de cada unidade de observação com desempenho médio em cada atributo, o índice multidimensional passa a ser dado como:

$$
I_{\beta}^{M}(X)=1-\left[\frac{1}{n} \sum\left[\left(\frac{\left[S_{\beta}\left(X_{i}\right)\right]}{S_{\beta}(\mu)}\right)^{1-\varepsilon}\right]\right]^{\frac{1}{1-\varepsilon}}
$$


onde $\varepsilon$ é o parâmetro que fornece o grau de aversão à desigualdade no conjunto de atributos que determinam a qualidade de vida do indivíduo.

A diferença entre $I_{\beta}^{M}(X)$ e $I_{\beta}^{U}(X)$ é o denominador, de acordo com Decancq, Decoster e Schokkaert (2006, p. 11), "Whereas the proposed index IM(Z) uses the composite indicator of a country with average performance on every indicator as reference point, the indicator obtained by the two step approach $\mathrm{IU}(\mathrm{Z})$ uses the average value of the composite indicator". Além disso, o índice da equação (6) não satisfaz, necessariamente, UM e CIM, ao passo que o índice da equação (8) nem sempre satisfaz o princípio Pigou-Dalton (DARDANONI, 1995 apud DECANCQ; DECOSTER; SCHOKKAERT, 2006).

A importância da construção de um índice de desigualdade que capte a desigualdade agregada reside na possibilidade de entender a qualidade de vida como um todo das unidades de observação, tendo em vista o efeito compensatório entre os atributos. Ou seja, dada a divergência do comportamento no tempo da desigualdade nas diferentes dimensões consideradas, a não agregação tornaria impossível extrair qualquer conclusão geral sobre a evolução da desigualdade (DECANCQ; DECOSTER; SCHOKKAERT, 2006). Essa constatação feita por Decancq (2011) demonstrou que apesar da elevação da desigualdade em parte dos atributos analisados, a desigualdade global decresceu, compensada por outros atributos. É nesse contexto que os resultados obtidos estão condicionados ao trade-off entre dimensões, funções de transformação e parâmetros considerados na estruturação do índice.

A relevância desta análise está em tornar possível o estabelecimento de paralelos de comparação sobre a qualidade de vida entre as unidades de observação, em termos distributivos, no tempo e no espaço, configurando-se, portanto, ferramentas úteis para governos e analistas (DECANCQ, 2011; DECANCQ; LUGO, 2010).

A agregação, pela criação de um índice, na abordagem multidimensional, foi aprovada pela maioria das pesquisas sobre o tema (PHAN, 2016). A metodologia e os parâmetros normativos explicitam o duplo modo de tratar e calcular o índice multidimensional da desigualdade: pela via direta, que considera uma função de avaliação social implícita à medida de desigualdade, como no Índice de Tsui (1995, 1999); ou pela via indireta de dois passos, que primeiro constrói um índice composto de qualidade de vida, para então aplicar uma medida tradicional de desigualdade unidimensional, por exemplo, os Índices de Bourguignon (1999) e Maasoumi (1986, 1999).

Observe-se aqui que os índices de desigualdade e de desigualdade multidimensional são construídos a partir de noções de bem-estar. Tendo em vista, porém, os questionamentos feitos na seção 2, sobre as dificuldades da teoria do valor-utilidade para tratar a desigualdade (SEN, 1973), é preciso destacar que aqui não se trata de conclusões da teoria neoclássica do bem-estar, calçadas nessa teoria do valor. A teoria do valor-utilidade, e mais 
particularmente a ideia de distribuição que é possível dela extrair, impede preocupações com desigualdade interpessoal. Cautelosos com relação a esses problemas, procuramos evitar, na construção do índice, análises que impliquem questões de preferências individuais ou que envolvam referência à teoria do valor baseada na utilidade marginal.

Os índices de desigualdade do tipo Atkinson, aos quais pertence o Índice de Desigualdade Unidimensional de Atkinson-Kolm-Sen (AKS), como todo índice de desigualdade, são construídos de forma a inferir sobre a maior ou menor desigualdade, quando não há dominância entre duas ou mais distribuições de um atributo qualquer ou de um conjunto de atributos. A noção de bem-estar social introduzida para desempatar distribuições onde não há dominância usa apenas o princípio de Pigou-Dalton, segundo o qual $\mathrm{R} \$ 1,00$ dado a uma pessoa mais pobre vale mais do que o mesmo real dado a uma pessoa rica. Valoriza, então, a redução da desigualdade para hierarquizar distribuições diferentes (Medeiros, 2012). Na abordagem multidimensional, o Princípio Pigou-Dalton satisfaz a situação em que a transferência da realização do bem-estar da unidade de observação mais realizada em termos dos atributos para o menos favorecido resultaria no acréscimo global da realização da amostra e, paralelamente, na redução da desigualdade (ARISTEI; BRACALENTE, 2011; LUGO, 2005; WEYMARK, 2004).

A redução da desigualdade pode ser julgada de diferentes maneiras e os índices do tipo AKS introduzem um indicador de aversão à desigualdade $\varepsilon$ para hierarquizar as distribuições. Com $\varepsilon \in \mathbb{R}_{+}$tal que: $\varepsilon=0$, a sociedade não tem aversão à desigualdade, ou seja, a sociedade seria indiferente à transferência de atributos entre as unidades de observação; $\varepsilon>0$, aceitação do princípio de transferência de Pigou-Dalton; $\varepsilon \rightarrow \infty$, aversão à desigualdade é máxima e a análise tende a se concentrar em mudanças nos grupos de unidades de observação que gozam de menos atributos.

É preciso assinalar, de novo, que $\varepsilon$ é definido por um juízo de valor, que é preciso ficar claro no momento do cálculo, mas não implica nenhum pressuposto relacionado à teoria do valor-utilidade, embora seja coerente também com ela (MEDEIROS, 2012).

Assim como nas referências dimensão por dimensão, a maior parte dos trabalhos que agregam a desigualdade e calculam um índice também se restringe ao estudo empírico entre países. Outro ponto em comum entre as duas abordagens é o fato de contemplarem como dimensões as que constituem o Índice de Desenvolvimento Humano (IDH). Os trabalhos partem da concepção de que os atributos renda, educação e saúde constituem o bem-estar das unidades de observação, a partir de onde é possível analisar e comparar o bem-estar entre países, bem como a desigualdade.

Em termos de trabalhos empíricos, a ausência de singularidade dos resultados empíricos dos estudos sobre o índice de desigualdade multidimensional se deve ao fato de usarem distintas dimensões, e distinta seleção dos parâmetros, da função de agregação e da ponderação das dimensões. Isso constitui um aspecto forte da abordagem, 
por aprofundar o valor informativo que ilustra a relevância das preocupações distributivas para esse tipo de análise (ARISTEI; BRANCALENTE, 2011; DECANCQ; DECOSTER; SCHOKKAERT, 2006).

Nesse contexto, Aristei e Bracalente (2011) analisaram a desigualdade multidimensional e o bem-estar ajustado, para diferentes combinações dos parâmetros que captam a substitutibilidade entre os atributos e a aversão da sociedade à desigualdade, na Itália e nas suas regiões, comparando os anos de 2004 e 2007. Ao considerar as dimensões saúde, renda e educação, os autores destacam ser um dos pioneiros a estender essa análise para o nível regional. Observam índices mais elevados de bem-estar na região Centro-Norte em detrimento da Sul, mas por considerar intervalos de confiança que se sobrepõem entre as demais regiões, não podem concluir comparativamente sobre elas. Os autores observaram também que um melhor desempenho no bem-estar era resultado tanto da seleção dos parâmetros de estimação quanto das melhorias na equidade da distribuição dos atributos.

Decancq, Decoster e Schokkaert (2006), analisando um grupo heterogêneo de países desenvolvidos e subdesenvolvidos entre 1975 e 2000, observaram que a desigualdade nas três dimensões mostra uma tendência diferente entre 1975 e 2000 . A combinação de nenhuma transformação da dimensão da renda, uma baixa substitutibilidade das dimensões e uma leve aversão à desigualdade leva a um aumento acentuado da desigualdade do bem-estar nos últimos anos.

Decancq (2011) investiga a evolução da desigualdade do bem-estar global entre 1980 e 2010. A evolução dos diferentes atributos apresenta um padrão distinto ao longo do tempo, o que justifica a criação de um índice global para captar o que ocorreu com a desigualdade geral ou agregada. Os resultados estão condicionados ao esquema de ponderação selecionado, ao procedimento de agregação e à transformação da dimensão da renda.

Lugo (2005) realiza um completo levantamento metodológico para a construção de índices multidimensionais de desigualdade e apresenta um teste empírico para a Argentina em 1991 e 2001. As conclusões do trabalho foram ambíguas, porque a redução ou acréscimo da desigualdade está condicionada aos parâmetros e índices utilizados. Ou seja, não há uma conclusão inequívoca sobre se houve melhora ou piora da distribuição do bem-estar entre os indivíduos na Argentina entre esses dois anos.

Phan (2016) analisa o Vietnã no período 1993-2008, sustentado na teoria da capacidade de Sen, na qual o bem-estar é entendido como resultado das capacidades pessoais e deve ser o foco central das análises da desigualdade. O autor afirma que a desigualdade aumentou consideravelmente no período analisado, principalmente na década de 1990, com forte contribuição do meio rural. Quanto ao bem-estar, as áreas urbanas experimentaram divergências em maior grau e mais rápido do que as áreas rurais. 
Jordá, Trueba e Sarabia (2013), para um grupo de países e suas respectivas regiões, analisaram a flutuação da desigualdade do IDH, entendido como a expressão do bemestar. Os resultados permitiram observar que a desigualdade no bem-estar diminuiu 40\% no período de 1980 a 2011, mesmo diante da estagnação observada nos anos 1990 . Nos anos pós-2000, o declínio foi evidente e a decomposição dos índices de desigualdade multidimensional mostrou que a mitigação da desigualdade se deveu principalmente à diminuição da desigualdade intrarregional.

\section{CONSIDERAÇÕES FINAIS}

Neste artigo, procuramos discutir a literatura sobre desigualdade multidimensional, justificando a importância da redução do problema e da construção de um índice que informe adequadamente as políticas públicas. Mostramos, inicialmente, que a desigualdade não é vista de forma consensual pelos economistas, havendo razões para que ela não seja encarada como um problema pelo mainstream em economia. Isso justifica a observação de Sen sobre a pouca pertinência do valor-utilidade para tratar a desigualdade, e o cuidado que teve o artigo em evitar a necessidade ou a utilização deste na construção do índice.

Ao contrário, a visão heterodoxa justifica a necessidade da redução das desigualdades via políticas públicas, não apenas como uma questão de justiça social, mas para a construção do interesse comum. Assim, a visão heterodoxa levou à introdução, no índice, de atributos econômicos e sociais, mas também de participação social e de interesse comum ou coletivo, sujeitos às limitações de disponibilidade de dados e possibilidades de mensuração.

A revisão de literatura permitiu ainda destacar a possibilidade de abordar o caráter multidimensional da desigualdade, tanto de forma desagregada, atributo por atributo, quanto de forma agregada, construindo um único índice a partir dos vários atributos. O uso das duas metodologias instrui melhor as políticas públicas porque, no primeiro caso, é possível visualizar a evolução de cada dimensão analisada, tirando conclusões sobre cada uma delas e informando sobre a necessidade de medidas de política específicas. No segundo caso, é possível verificar até que ponto aumentos da desigualdade em uma dimensão podem ser contrabalançados por reduções em outras, dando melhor informação sobre a qualidade de vida dos indivíduos ou dos municípios como um todo, além de permitir comparações entre unidades de observações diferentes. 


\section{REFERÊNCIAS}

AABERG, R.; BRANDOLINI, A. Multidimensional poverty and inequality. Temi di Discussione, Roma, Banca D’Italia, n. 976, 2014.

AMADO, A. M. Disparate regional development in Brazil. A monetary production approach. Aldershot: Ashgate, 1997.

ARISTEI, D.; BRACALENTE, B. Measuring multidimensional inequality and well-being: Methods and empirical applications to Italian Regions. Statistica, v. 71, n. 2, p. 239-266, 2011.

ATKINSON, A. B. Desigualdade. São Paulo: Leya, 2016.

ATKINSON, A. B. On the measurement of inequality. Journal of Economic Theory, v. 2, n. 3, p. 244-263, 1970.

ATKINSON, A. B. Poverty. In: DURLAUF, S. N.; BLUME, L. E. (Eds.). The New Palgrave Dictionary of Economics. 3. ed. New York: Palgrave Macmillan, 2008. p. 544-556.

ATKINSON, A. B.; Bourguignon, F. The comparison of multidimensioned distributions of economic status. Review of Economic Studies, v. 49, n. 2, p. 183-201, 1982.

BARROS, R. P.; CARVALHO, M.; FRANCO, S. Pobreza multidimensional no Brasil. Texto para Discussão, IPEA, n. 1227, 2006.

BATISTA, H. R. Desigualdade multidimensional no Brasil: questões metodológicas e empíricas. 2018. Tese (Doutorado em Economia) - Universidade de Brasília, Brasília, DF, 2018.

BOURGUIGNON, F. Comment to 'Multidimensioned Approaches to Welfare Analysis' by Maasoumi, E. In: SILBER, J. (Ed). Handbook of income inequality measurement. Dordrecht: Kluwer Academic, 1999. p. 477-484.

CAMPELLO, T. et al. Faces da desigualdade no Brasil: um olhar sobre os que ficam para trás. Saúde Debate, v. 42, n. 3, p. 54-66, 2018.

COBO, B.; ATHIAS, L.; MATTOS, G. G. Multidimensional poverty in Brazil through fundamental social rights compliance: an analytic proposal. In: INTERNATIONAL CONFERENCE INCOME, WEALTH AND WELL-BEING IN LATIN AMERICA, 2013, Rio de Janeiro. Anais [...]. Rio de Janeiro: IBGE, 2013. p. 1-24.

COMIM, F.; BAGOLIN, I. Aspectos qualitativos da pobreza no Rio Grande do Sul. Ensaios FEE, v. 23, p. 467-490, 2002.

DECANCQ, K. Essays on the measurement of multidimensional inequality. 2009. Proefschrift (Ph.D. in de Economische Wetenschappen) - Katholieke Universiteit Leuven, Leuven, 2009.

DECANCQ, K. Global inequality: a multidimensional perspective. Leuven CES Discussion Paper Series 11.09. Leuven: Katholieke Universiteit Leuven, 2011.

DECANCQ, K.; DECOSTER, A.; SCHOKKAERT, E. The evolution of World Inequality in Well-being. Leuven CES Discussion Paper Series 07.04. Leuven: Katholieke Universiteit Leuven, 2006.

DECANCQ, K.; LUGO, A. M. Weights in multidimensional indices of wellbeing: an overview. Econometric Reviews, v. 32, n. 1, p. 7-34, 2012.

DEDECCA, C. S. A redução da desigualdade e seus desafios. Texto para Discussão, IPEA, Rio de Janeiro, n. 2031, 2015. 
DEDECCA, C. S. Notas sobre crescimento, desenvolvimento e desigualdades no Brasil. In: BIASOTO JUNIOR; G. SILVA, L. A. P. (Orgs.). Aporias para o planejamento público. São Paulo: FUNDAP, 2013.

DUCLOS, J. Y.; ARAAR, A. Economic Studies in Inequality Social Exclusion and Well-Being. In: DUCLOS, J. Y.; ARAAR, A. Poverty and equity: measurement, policy and estimation with DAD. New York: Springer, 2006.

EASTERLIN, R. The worldwide standard of living since 1800. Journal of Economic Perspectives, v. 14, n. 1, p. 7-26, 2000.

FERREIRA, R. N. Os limites da renda como indicador de bem-estar social e desigualdade nos municípios brasileiros. Tese (Doutorado em Geografia) - Universidade Federal de Minas Gerais, Belo Horizonte, MG, 2017.

FERREIRA, F. H. G.; LUGO, M. A. Multidimensional poverty analysis: looking for a middle ground. World Bank Research Observer, v. 28, n. 2, p. 220-235, 2013.

GORDON, D.; Pantazis, C. (eds.). Breadline Britain in the 1990s. Bristol: Summerleaze House Books, 1997.

GUIMARÃES, J. R. S.; JANNUZZI, P. M. IDH, indicadores sintéticos e suas aplicações em políticas públicas: uma análise crítica. Revista de Estudos Urbanos e Regionais, v. 7, n. 1, p. 73-90, 2004.

HAYEK, F. A. Os fundamentos da liberdade. São Paulo: Visão, 1983.

HOBIJN, B.; FRANSES, P. Are living standards converging? Structural Change and Economic Dynamics, v. 12, n. 2, p. 171-200, 2001.

IBGE - INSTITUTO BRASILEIRO DE GEOGRAFIA E ESTATÍSTICA. Estatísticas. Rio de Janeiro: IBGE, 2017. Disponível em: https://www.ibge.gov.br/estatisticas/downloadsestatisticas.html. Acesso em: 9 abr. 2020.

JANNUZZI, P. M. Considerações sobre o uso, mau uso e abuso dos Indicadores sociais na formulação e avaliação de políticas públicas municipais. Revista de Administração Pública, v. 36, n. 1, p. 51-72, 2002.

JANNUZZI, P. M. Indicadores para diagnóstico, monitoramento e avaliação de programas sociais no Brasil. Revista do Serviço Público, v. 56, n. 2, p. 137-160, 2005.

JANNUZZI, P. M. Indicadores no ciclo de políticas sociais e programas sociais no Brasil. In: SIMÕES, A.; ALKMIM, A. C. (Orgs.). Indicadores sociais: passado, presente e futuro. Rio de Janeiro: IBGE, 2017.

JANNUZZI, P. M. A importância da informação estatística para as políticas sociais no Brasil: breve reflexão sobre a experiência do passado para considerar no presente. Revista Brasileira de Estudos de População, v. 35, n. 1, p. 1-10, 2018.

KAHNEMAN, D.; Krueger, A. B. Developments in the measurements of subjective well-being. Journal of Economic Perspectives, v. 20, n. 1, p. 3-24, 2006.

KOLM, S. C. Multidimensional Egalitarianisms. The Quarterly Journal of Economics, v. 91, n. 1, p. 1-13, 1977.

LAVINAS, L. Pobreza: métricas e evolução recente no Brasil e no Nordeste. Cadernos do Desenvolvimento, v. 5, n. 7, p. 126-148, 2010. 
LUCAS, R. The industrial revolution: past and future. Annual Report Essay, Federal Reserve Bank of Minneapolis, v. 18, p. 5-20, 2004.

LUGO, M. A. Comparing multidimensional indices of inequality: methods and application. Society for the Study of Economic Inequality Working Paper Series. ECINEQ WP 2005 - 14. 2005. Palma de Mallorca: ECINEQ, 2005.

MAASOUMI, E. Multidimensioned approaches to welfare analysis. In: SILBER, J. (Ed.). Handbook of income inequality measurement. Boston: Kluwer Academic, 1999. p. 437-477.

MAASOUMI, E. The measurement and decomposition of multi-dimensional inequality. Econometrica, v. 54, n. 4, p. 991-997, 1986.

MACK, J.; LANSLEY, S. Poor Britain. London: G. Allen \& Unwin, 1985.

MEDEIROS, M. O que faz os ricos ricos. O outro lado da desigualdade brasileira. São Paulo: Anpocs, 2005.

MEDEIROS, M. Medidas de desigualdade e pobreza. Brasília: EdUnB, 2012.

MEDEIROS, M.; SOUZA, P. H. G. F.; CASTRO, F. A. A estabilidade da desigualdade de renda no Brasil, 2006 a 2012: estimativa com dados do imposto de renda e pesquisas domiciliares. Ciência e Saúde Coletiva, v. 4, n. 20, p. 971-986, 2015.

MOLLO, M. L. R. Changing dominant paradigm in economics. Cadmus, v. 2, n. 1, p. 119-133, 2015.

MOLLO, M. L. R.; AMADO, A. M. Globalização e blocos regionais: considerações teóricas e conclusões de política econômica. Estudos Econômicos, v. 32, v. 1, p. 127-166, 2001.

MONTEIRO, C. A. A dimensão da pobreza, da fome e da desnutrição no Brasil. Estudos Avançados, v. 9, n. 24, p. 195-207, 1995.

NARAYAN, D. Voices of the poor: Can Anyone Hear Us? Washington, DC: World Bank Publication, 2000.

NERI, M. C. Políticas estruturais de combate à pobreza no Brasil. In: HENRIQUES, R. (Org.). Desigualdade e Pobreza no Brasil. Rio de Janeiro: IPEA, 2000. p. 503-526.

NERI, M. C. Desigualdade de renda na década. Evolução dos indicadores sociais baseados em renda. Rio de Janeiro: FGV/CPS, 2011.

NEUMAYER, E. Beyond income: convergence in living standards, big time. Structural Change and Economic Dynamics, v. 14, n. 3, p. 275-296, 2003.

ORSHANSKY, M. Counting the poor: another look at the poverty profile. Social Security Bulletin, v. 28, n. 1, p. 3-29, 1965.

PHAN, V. P. An investigation of the measurement of inequality and the causal effects of the pro-poor national targeted programs on inequality in Vietnam. 2016. Thesis (Doctor of Philosophy) School of Accounting, Economics and Finance, University of Wollongong, Wollongong, 2016. Disponível em: http://ro.uow.edu.au/theses/4890. Acesso em: 15 jan. 2017.

PIKETTY, T. Le capital au siècle XXI. Paris: Seuil, 2013.

ROWNTREE, B. S. Poverty: a study of town life. London: MacMillan, 1901. 
ROUSSEAU, J. J. Do contrato social. Discurso sobre a Economia Política. Curitiba: Hemus, 2000.

RYTEN, J. Should there be a human development index? In: STATISTIQUE, DEVELOPPEMENT ET DROITS DE L'HOMME SEMINAR, 2000, Montreaux. Annales [...]. [s. n.]: Montreaux, 2000.

SALAHUDDIN, T.; ZAMAN, A. Multidimensional poverty measurement in Pakistan: time series trends and breakdown. The Pakistan Development Review, v. 51, n. 4, p. 493-504, 2012. Disponível em: http://www.pide.org.pk/pdf/PDR/2012/Volume4/493-504.pdf. Acesso em: 3 jul. 2015.

SCHOKKAERT, E. Capabilities and satisfaction with life. Journal of Human Development, v. 8, n. 5 , p. $415-430,2007$.

SEN, A. On economic inequality. Oxford: Clarendon Press, 1973.

SEN, A. K. Poor, relatively speaking. Oxford Economic Papers, v. 35, n. 2, p. 153-169, 1983.

SERRA, A. S.; YALONETZKY, G. I; BELIK, W. Multidimensional poverty in Brazil, 2000/2010. In: ENCONTRO NACIONAL DE ECONOMIA, 45., 2017, Natal. Anais [...]. Niterói: ANPEC, 2017.

SETH, S. Multidimensional inequality. Nashville; Oxford: Vanderbilt University; OPHI, 2009. Disponível em: http://www.ophi.org.uk/wp-content/uploads/Multidimensional-Inequality_ SS.pdf. Acesso em: 7 jan. 2017.

SIAL, M. H.; NOREEN, A.; AWAN, R. U. Measuring multidimensional poverty and inequality in Pakistan. The Pakistan Development Review, v. 54, n. 4, p. 685-698, 2015.

SILVA, J. J.; PINHO, B. M. A.; SILVA, D. B. N. Multidimensional poverty in Brazil: analysis of the period 2004-2015. Brazilian Journal of Political Economy, v. 40, n.1, p. 138-160, 2020.

SILVA, P. L. N; PESSOA, D. G. C.; LILA, M. F. Análise estatística de dados da PNAD: incorporando a estrutura do plano amostral. Ciência e Saúde Coletiva, v. 7, n. 4, p. 659-670, 2002.

SILVEIRA, F. G. Equidade fiscal: impactos distributivos da tributação e do gasto social. Brasília: ESAF; Tesouro Nacional, 2012. (XVII Prêmio Tesouro Nacional 2012).

SILVEIRA, F. G. Tributação, previdência e assistência sociais: impactos distributivos. Tese (Doutorado em Economia) - Instituto de Economia, Universidade Estadual de Campinas, Campinas, 2008.

SILVEIRA, F. G.; PASSOS, L.; GUEDES, D. R. Tax reform in Brazil: where to begin? Saúde e Debate, v. 42, n. 3, p. 212-225, 2018.

SILVEIRA, F. G. et al. Fiscal equity: distributional impacts of taxation and social spending in Brazil. International Policy Centre for Inclusive Growth. Working Papers 115. New York: United Nations Development Programme, 2013.

SOUZA, P. H. G. F. Income distribution according to Brazilian household surveys: harmonization and comparison of Census, PNAD and POF data. Revista Brasileira de Estudos de População, v. 32, n. 1, p. 165-188, 2015.

STIGLITZ, J. E. Alargando a nossa reflexão sobre vulnerabilidade. In: PNUD - PROGRAMA DAS NAÇÕES UNIDAS PARA O DESENVOLVIMENTO. Relatório de Desenvolvimento Humano 2014. New York: PNUD, 2014. p. 84-85. 
STIGLITZ, J. E.; A. SEN; FITOUSSI, J. P. Report by the Commission on the measurement of economic performance and social progress. Paris: Commission on the Measurement of Economic Performance and Social Progress, 2009.

SUPPA, N. Walls of glass. Measuring Deprivation in Social Participation. OPHI Research in Progress 49a. Oxford: University of Oxford, 2017.

TROVÃO, C. J. B. M. Desigualdade multidimensional: uma abordagem keynesiana para o seu enfrentamento. Tese (Doutorado em Economia) - Instituto de Economia, Universidade Estadual de Campinas, Campinas, 2015.

TOWNSEND, P. Poverty in the United Kingdom: a survey of household resources and standards of living. Berkeley: University of California Press, 1979.

TSUI, K. Y. Multidimensional generalizations of the relative and absolute inequality indices: the Atkinson-Kolm-Sen approach. Journal of Economic Theory, v. 67, n. 1, p. 251-265, 1995.

TSUI, K. Y. Multidimensional inequality and multidimensional generalized entropy measures: an axiomatic derivation. Social Choice and Welfare, v. 16, n. 1, p. 145-157, 1999.

VAZ, A. C. N. Estudo Técnico n. 24/2012. Metodologias de estimação de população em extrema pobreza: um estudo dos "Sem Declaração" e dos "Sem Rendimento" na PNAD. Brasília: Ministério do Desenvolvimento Social e Combate à Fome, 2013.

WEYMARK, J. A. The normative approach to the measurement of multidimensional inequality. Vanderbilt University Department of Economics Working Papers 0314. Nashville: Vanderbilt University, 2004. 